\title{
GOOD REgUlation REFLECTS WORDS IN ACTION
}

\author{
Mirko Pečarič ${ }^{1}$
}

\begin{abstract}
Given the impossibility of binary "yes" and "no" classical general legal rules to anticipate and address the future path of law, this paper imitates the adaptive human nature and frames future legal actions on it. Given this human trait, this paper presents some predispositions for substance and actions that are based on the systemic/cybernetic approach. The latter prioritises values, goals and their weights, with controllable thresholds that, based on feedback loops between events, facts, and intentions, activate different preestablished (legal) scenarios. The paper develops new responses to changed conditions (responsiveness, adaptability, agility and robustness); the first are needed in the law due to inevitability of dynamic changes to present some adaptive regulatory techniques, which could be implemented in practical systems. The paper concludes that such techniques can be used in the law used as sunset clauses, legal experiments, emergent strategies, negative scenarios, adaptable norms, Henry VII clauses, public opinion within collective intelligence and legal experiments. They all can address changed conditions in the environment.
\end{abstract}

\section{Keywords}

Responsiveness, Adaptability, Agility, Robustness, Adaptive Regulation, Emergent Strategies, Negative Scenarios

In warfare, there are no constant conditions. - Sun Tzu

\section{Introduction}

In the post-industrial and post-Covid-19 (un)healthy world, it is not clear whether we live in a post-democratic, ordinance-based world; many countries in the urge to quickly adapt to Covid-19 conditions, did this with the secondary legislation, in the form of statutory instruments, ordinances, executive orders or differently named modes of regulation that skipped the legislator's approval. Centuries ago, a state's duty was power and protection. After WWII, it was to enable work and provide opportunities, in the last two or three decades the emphasis was on privatisation, liberalisation and deregulation. Although the

\footnotetext{
${ }^{1}$ University of Ljubljana, Gosarjeva ulica 5, SI-1000 Ljubljana, Slovenia. E-mail: mirko.pecaric @ fu.uni-lj.si.
} 
information area now blossoms, it seems the law does not know what to do with it; information (and now viruses) spread regardless of national borders, and the classical states' power and protection are mostly unfit to deal with such "invisible migrants" that effortlessly transfer countries' borders. It seems as if the primary legislation was unable to quickly adapt to the changed conditions. In this line of thought, this paper gives some predispositions how legislation and regulation can be more adaptable. The paper intends to present the exploratory, experimental and adaptive human nature of the law that is instead of the history and the present focused on the future. In the next sections five elements (presented in an italic statement at the beginning of each paragraph) are basic frames to deal with legal topics that could be more relevant in the future. In this manner, this paper presents also predispositions for action in the third section, for management of which a systemic approach is presented as the sine qua non for good regulation in the fourth section to be able to present appropriate responses to changed conditions in the fifth section. Finally, based on them, also some adaptive regulatory techniques in the sixth section are presented. Five elements - presented in an italic statement at the beginning of each paragraph - are basic frames to deal with legal topics that could be more relevant in the future. In this manner, this paper presents predispositions for action in the next section, for management of which a systemic approach is presented as the sine qua non for good regulation in the third section to be able to present appropriate responses to changed conditions in the fourth section. Finally, based on them, also some adaptive regulatory techniques in the fifth section are presented, after which the conclusion follows.

\section{Predispositions for Substance}

Focus on a decision and its context. Goals are changing; they can be quite different in different (even neighbouring) countries, so one step behind them should be made to know how they (can be) change(d). It may still be the task of philosophy to make visible what we directly look all the time (Foucault, 2013), but the task of science should be no more to discover what is hidden, but to make more manageable what is in front of our eyes. One example is the mentioned Covid-19 crisis: etymologically "crisis" comes from the Greek krísis "act of separating, decision, judgment, outcome, sudden change" (MerriamWebster, 2020). Initially, it signifies a crucial moment in the development of a disease, but in its essence, it still carries a fundamental element of separation, deciding between what is important and what needs to be separated from it. Its essence is thus the same as for "decision" (lat. decidere to cut off, from de- + caedere to cut) (Merriam-Webster, 2020); both should be connected with a broader "context perspective" that centres on how the societal system of decision processes affects how a particular problem is addressed (Gorddard, Colloff, Wise, Ware and Dunlop, 2016). Laws, in general, should reflect human reason, the united strength of individuals; they should be adapted to the people as they are framed for them, and be relative to the nature and principles of each government's situation. These relations constitute the Spirit of Laws (Montesquieu, 2004). In the perfect world, laws interchangeable emulate the people's spirit: they are founded on perfect information that echoes all relevant conditions of their time, i.e., the people's being in its context. In a not so perfect world, there are also people's errors and free will present, but this 
should not be an obstacle for trying to reflect human as much as possible (the more people involved, the better is for a final decision, because extremes on both sides mutually exclude themselves). The problem of controlling a system's output given the external inflows may be the central problem of lege artis. A classical setup works in the context of linear, time-invariant and finite-dimensional systems, where commands and instabilities range over a set of known possible states. Even here error measurement is present, while in the nonlinear environment - where reign unknown amplitudes and phases - known/possible states are vaguer, while feedback in the classical sense of measuring differences between a wanted and a present state is absent. In this frame, output legislation should be designed on: i) feedback, ii) the determination of conditions of possible oscillations, iii) designed actions as a stable response to these oscillations, and iv) designed actions as compensators and/or proxies to prior objectives.

Focus on goals and frames from which goals are established. The human intuition, emotions, values, and reason should also not be disregarded here, as they all form the inseparable set of human thinking and action. Münsterberg in 1908 complained that the "lawyer and the judge and the juryman are sure that they do not need the experimental psychologist... They go on thinking that their legal instinct and their common sense supplies them with all that is needed and somewhat more" (Münsterberg, 1908, pp. 10-11). In history, laws were passed mainly with intuitive knowledge, where suspicion verging on hostility toward psychology and statistics can still be found (Gigerenzer and Engel, 2006). However, from 2010 on "nudge units" or "behavioural insight teams" that apply behavioural science to public policy have been created (first in the Cabinet Office in 2010 by David Cameron's government and then in the United States, the United Kingdom, Germany, and other nations) (Sunstein, 2016; Sunstein and Reisch, 2019), and evidencebased decision-making as the science-informed practice of decision-making (Banasiewicz, 2019; Rousseau, 2013) is also known. On the other hand, randomness and unconsciousness also run the context and our lives in it (Mlodinow, 2008; Mlodinow, 2013), sometimes even towards the illusion of certainty (Rifkin and Bouwer, 2007; Pasnau, 2018) that cannot be disputed, but the human survival per se reflects also ability to cope with the multifaceted, non-linear, complex and non-stop emerging changes (as the above Sun Tzu's saying shows). Out of the exploratory instincts that allowed our ancestors to prosper hundreds of thousands of years ago, humans developed a cognitive style that Mlodinow terms elastic thinking, a collection of traits and abilities that include neophilia (an affinity for novelty), schizotypy (a tendency toward unusual perception), imagination and idea generation, pattern recognition, mental fluency, divergent thinking, and integrative thinking (Mlodinow, 2018). So, how good such mental states can be included in legislation? This paper argues that a more science-based approach in the law should walk hand-in-hand with the exploratory, experimental and adaptive human nature that served us well so far.

Use the adaptive human nature in law. Science and evidence-based approaches (especially in the field of social science due to the human's freedom, autonomy, and free will) have limited value, so it all the more important to have them in the first place. The closest to this aim could be the governmental risk registers and databases, risk assessment systems, or 
automated monitoring systems (that are mainly present in the military, intelligence, weather forecast, traffic, and greenhouse gas), while the computerised modelling, projection, and forecasting systems in the law are absent in the majority of cases. While an appropriate design of institutional machinery is missing, there are no real obstacles to go a few steps further. Although there is no single correct way of conceiving risk regulation regimes (Hood, Rothstein and Baldwin, 2001), a regulatory analysis could be based on the systems theory approach, cybernetics (as the science of control and communication), variety and/or multiple perspectives and independent sources to provide diverse approaches with an adaptive capacity to deal with complex circumstances (Lodge and Wegrich, 2012) a la Covid-19 crisis. $^{2}$ Nowadays, bureaucratic expertise lost this proficiency, because the personal knowledge and informal "oral wisdom" cannot deal with multiple pearls of wisdom of others in the complex environment. To balance this relation, a digital approach could be helpful to construct digital expert systems that use complex modelling and decision algorithms to help inform experts' choices (Dunleavy, Margetts, Tinkler and Bastow, 2006) and/or rely on various techniques of extraction of information from multiple data sources.

Frame future actions. This paper presents frames in which legislation/regulation could administer future doings that will show their effects in a flexible, complex, and most importantly - unknowable environment. From the point of usual legal parlance, the generality, publicity, accessibility, comprehensibility, consistency and compliance of laws with legal obligations are put aside, because the focus is on the possible and congruent rules vis-à-vis their enactment and future application. Organisational aspects like the political will, a governmental office for regulatory affairs, that is along with lawyers, equipped also with economists, psychologists, informatics, and other relevant profiles, all grouped in the Centre of government (as not only technical, administrative support for the Prime Minister, but as the central, coordinative and regulatory [nudge] centre), are also put aside. The investigation of social control addresses here not only how people define and respond to deviant behaviour (Horwitz, 2013), but also how different techniques to achieve goals can be used. These techniques (as the adaptive, dynamic decision support systems) are useful insofar as they can give a useful answer to empirical phenomena, more than can they explain or even predict them (the Covid-19 was unpredictable, but there were/are efficient prevention techniques). The point is not to fully predict the objective future (as this is

\footnotetext{
${ }^{2}$ The adaptive element is seen in the Constitutional Court of the Republic of Slovenia decision with which it suspended the implementation of Article 7 of the Ordinance on the temporary prohibition of the gathering of people at public meetings at public events and other events in public places in the Republic of Slovenia and prohibition of movement outside the municipalities (OJ, no. 38/20, 51/20 in 52/20) (the mentioned Article determined the Ordinance's limitations are valid until the Government by a resolution publishes their end in the OJ of the Republic of Slovenia). The suspension of Article was carried out in such a way that "the Government must without delay after notification of this decision and then, at least every seven days, check, on the basis of the opinion of the profession, whether the measures introduced are still necessary to achieve the objectives and extend, amend or abolish them considering professional reasons. The Government must inform the public thereof" (at 28). This element of adaptation (along with the people's respect on limitations) caused that Slovenia has only 51 deaths/one million of population comparing to 539 deaths in Italy, which is Slovenia's neighboring country.
} 
impossible) but to have appropriate responses at hand when the time comes. Regulators ideally always struggle to accommodate legal rules in their environments, but in practice, their techniques should reflect the basic human element of adaptation to be effective. The better, smart, responsive, meta regulation, the removal of unnecessary costs or burdens, the principle of proportionality, equality and other regulatory approaches can be hence just the different views on adaptation given a rule's context. For the past/future actions, adaptation means curative/preventive care. This paper will be focused on adaptation in the latter sense, which is mainly disregarded in works that address regulation (Baldwin, Cave and Lodge, 2012; Baldwin, Cave and Lodge, 2013; Breyer, Stewart, Sunstein and Vermeule, 2006; Dunning, 2012; Lazarsfeld, 1949; Lodge and Wegrich, 2012; Morgan and Yeung, 2007; Ogus, 2003). A good regulatory approach more than it can explain the future's a behaviour, it can embrace it in an applicable, testable and systematic way. In this manner, this paper enumerates and explains some regulatory approaches that more/less enable real-time, continuous and interrelated decisions in dynamic and complex environments. With this possibility, they could be (in)formally used for the future's legislation/regulation.

Be attentive to anticipative regulatory techniques. Having this goal in mind this paper presents some regulatory anticipative regulatory techniques that are based on the systemic and/or cybernetic approach. Even when they are not enacted as the law, they could serve as valuable inputs for it (or for other strategic documents). In this manner, it is urgent also to involve other people into decision-making not only due to the legitimising element but to enable diverse views on legal solutions. Decision-makers generally know quite well their fields, but often not so much or differently than citizens. Before they complete the rules, they need to acquire public comments and learn on widely dispersed peoples' views. As this idea is widely known in the form of public participation and similar notions, practice per se and/or the lack of the former in the latter point to a deeper truth. If people's essence is Plato's mix of logos (logic, reason), thymos (emotion, spiritedness), and eros (appetitive, desire) (Plato, 2000) it is all the more relevant these elements are observed in real (active/passive) actions. One additional step is thus to observe and measure the people's real behaviour, not only their comments. In this manner, Emerson wrote that "what you do speaks so loudly, I cannot hear what you say" (Emerson, 1875). This saying presupposes an active component that ties together theory and practice. Without a preformed methodology, decision-makers are like any other person. While people make mistakes, decision-makers' a formal approach cannot diminish them. They - due to the formality of their roles (which enables them to make public decisions in the first place) - even tend to hold overly favourable views on their abilities. The above-average effect is known as the Lake Wobegon effect, where in a fictional town "all women are strong, all men are good-looking, and all children are above average" (Keillor, 2016). Kruger and Dunning scientifically confirmed this (Kruger and Dunning, 1999) as a cognitive bias in which unskilled people not only reach erroneous conclusions but their incompetence as such robs them of the cognitive capacity to realise this (the Dunning-Kruger effect). As in personal matters the same stands for the public ones: people can hence spot an "expert" or a decision as "good", but a real state of affairs can be quite different. Why 
would there be any problems at all still present if there are so many experts? Although the presence of ranking international indexes can diminish the governmental version of Lake Wobegon (the above-average or overconfidence effect), the Dunning-Kruger effect stays: governmental incompetence can progress up to a point where the present government thinks on itself as the best or irreplaceable. A version of this effect can be traced also in the field of legislation/regulation (here used interchangeably), where the previous centuries' regulatory approaches (where the majority of things/changes/amendments is still made manually, i.e. each change through its specific procedure) are still mainly intuitively used for nowadays more complex (technologically more advanced, global, invisible) problems, without realising the inefficiency of such (irrational, non-objective and non-dynamical) approaches $^{3}$ that cannot provide the law's integrity and trust suitable for the 21 st century. Legal science should hence publicly share its intentions and doings - similar to personal integrity in private relations.

\section{Predispositions for Actions}

Quality is something that someone does (Fukuyama, 2014); with this, it also fits into the cybernetic idea that the (real) purpose of the system is what it does (Beer, 2002). Between legal intentions (statements) and legal results the latter "speak" for themselves, similarly as a man is what he does, not what he says. Good results can result either from a good or a bad decision and the contrary, so it matters to know how results are formed more than to know how a decision is made. Below are therefore given some predispositions that could reflect the mentioned connection and/or should be present in front of elaboration of problems, to know from what a problem is made in the first place, to know its context, to know what kind of information characterises a relevant situation as such.

One way is to be attentive to actions: the latter usually better reflect intentions or meaning than words alone. The Index of happiness shows in this manner not only the emotional state of mind but de facto comes from solving problems. Active engagement or "[t]rue happiness occurs only when you find the problems you enjoy having and enjoy solving" (Manson, 2016). People who solve, who act, are thus also happy. It is no surprise that states with the high index of happiness are ranked high also in the rule of law index: their legal system works - it solves problems. To be attentive on the action-solving problems, one has to pay attention not only to the action component but to four different combinations to establish connections in this relation: the action-solved problem, action-unsolved problem, inaction-solved problem and inaction-unsolved problem. A problem can be solved hence by action or inaction, so it is important to know from where results emerge. States with the high rule of law index are not more "legal" than others: they just solve problems

\footnotetext{
${ }^{3}$ In this objection fits also scientific writing - to be published, a paper should have many scholars' citations and statistical analysis to ensure an apparently scientific approach. But what is a sample of few dozen citations vis-à-vis millions of people (there is a large body of research that demonstrates superiority of ordinary citizens over expert opinions)? If at least a major part of statistical analysis in the field of social science was operative and repeatable, researched problems would be solved. But they are not. Social science is different from the natural one. In the first the people's free will is a major element of unpredictability. It is not about denying quotes and statistical analysis per se, but about finding the more or less objective paths to step further.
} 
better, their methodologies (modus operandi) are better. It is thus not the law per se that should be studied (vis-à-vis results), but its ways of addressing and solving problems, its regulatory techniques. As the latter regulate future cases, previous actions are not always a good predictor for the future ones. When "the future happens" the previously planned regulatory actions may not fit in a new frame. Here techniques like future scenarios (two or more ways of doing are planned given different circumstances, e.g., what a country should do when there are 50, 500, 5.000, or 50.000 illegal migrants on its territory), sunset clauses, legal experiments and probability (latter in the form of Bayes theorem or Bayesian nets) can be helpful. Overconfidence can be minimised also with some logical approaches: by the consideration of a base rate that reflects some specific information through the generic one (and aligns it more appropriately with actual rates of accuracy), the enumeration of reasons against a solution and/or not to disregard information that disconfirms, not only confirms a hypothesis. In such ways, ignoring what one does not know is harder, and on the other hand, experienced people acquire by observing how situations respond to their actions can be more correct than just post obvious search for arguments that confirm their initial intentions. The use of techniques can more objectively calibrate a factual state of affairs, but it should be noted that even in this way all possible outcomes are unknown due to the inapplicability of all alternative actions.

The second is independence. Even if one person/expert is exceptional at one thing, it is highly probable he is average or below at other things. The people's notions of their skills and knowledge are many times not only far from perfect indicators of their actual proficiency, but in the worst cases their incompetence causes the inability to know on this incompetence - this is known as the anosognosia (a deficit of self-awareness; gr. $a$, "without", nosos, "disease" and gnōsis, "knowledge") of everyday life (Dunning, 2012). To progress, a multitude of people should be involved to fill "all dots in a picture", to "cancel out" each other's over- and underestimations. People may not want to abandon their conclusions because they are "obvious", but when one answer and its opposite appears equally obvious, then "something is wrong with the entire argument of obviousness" (Lazarsfeld, 1949, p. 380). When all (although democratically established) sides have equal or similar (contra) arguments, a final (majority) decision is wrong (from a factual point of view). These fillings should be made by cooperation, not in a manner we are accustomed through majority votes; they should be made independently: people's opinions and/or actions should not be submitted to other people's (or nowadays to already present superintelligent systems) influence. Dependence diminishes the personal exceptionalism and the variety (which both emanate from independence) needed to have the sharpest picture.

Super-intelligence that can be present in big data connected with algorithms cannot be compared with the distributed, collective intelligence of the entire population that has more diversity and quality of solutions... For collective intelligence to work, information searches and decisionmaking by individuals must occur independently. If our judgments and decisions are predetermined by algorithms, however, this truly leads to a brainwashing of the people. Intelligent beings are downgraded to mere receivers of commands, who automatically respond to stimuli (Dirk Helbing, 
Gerd Gigerenzer, Ernst Hafen, Michael Hagner, Yvonne Hofstetter, Jeroen van den Hoven, Roberto V. Zicari, Andrej Zwitter, 2020).

The present law should not be based only on "reality" (because the latter depends on its predispositions, in the law many times on a coalition's majority), but on evidence-based management that should be - due to its social nature - constructed socially, based on the public participation, collective intelligence (that prioritise values, goals and their weights) and controllable thresholds that based on feedback loops between events/facts and intentions activate different, pre-established legal scenarios (this is the third way). Otherwise, the law is just superstitious, socially destructive, and non-controllable, where the limit for a ruling majority's "polarised stories" becomes the sky itself, where also current popularity of government depends on the people's whim. Endeavours to control our thoughts from the top-down level are hard due to the problems' complexity, its widespread, distributive presence on multiple levels (with their local modus operandi and control), their combinations and exponential effects that cause the inability of real-time optimisation. On the other hand, individuals who value freedom and autonomy might not know all information needed to make a relevant decision. Here, the idea that "democratic system is needed with the appropriate transparency and democratic control" could be at hand. Yes, this is heard many times, but there could be the already mentioned discrepancy present between actions and words if these words are just as mantras repeated all the time. A focus on action could ask: transparency (or any other notion) for what, for whom, where, when, in what way, how and why? A precondition for transparency is not just data served or published by the government, but the right to self-determination of what counts as (important) data (a precondition is [digital] access to information). "The right of individual self-development can only be exercised by those who have control over their lives, which presupposes informational self-determination” (Dirk Helbing, Gerd Gigerenzer, Ernst Hafen, Michael Hagner, Yvonne Hofstetter, Jeroen van den Hoven, Roberto V. Zicari, Andrej Zwitter, 2020), and/or the right of self-determination of what counts as information. Such independent prioritisation of information (and hence also of problems) leads towards a better life of all, not just towards a better government's popularity. The trick is that by addressing the first you get also the second - it just takes a little more time - but it also lasts more time. Given a limited amount of time, it is not so efficient for a present government to point at apparent wrongdoers (of past defects) instead of taking (the present) responsibility for solving these problems. It is harder to solve the latter when they are deemed to be outside of government's choosing, but not when there is empowered responsibility for things that happen in a government's mandate (no matter of outer conditions). "We don't always control what happens to us. But we always control how we interpret what happens to us, as well as how we respond. Whether we consciously recognize it or not, we are always responsible for our experiences" (Manson, 2016). ${ }^{4}$ And the same stands for the government: the point is it always should take an active role in

\footnotetext{
${ }^{4}$ Ralph Waldo Emerson's statement that "You are what you think" can be prolonged to say that "you are responsible also for coming to such conclusions". Although someone else could be blamed for (past) faults, it is our (present) responsibility to get better again.
} 
what is occurring to and within the government, regardless of a doer. This is the only way to get responsibility with power and not vice versa. Reactions to Covid-19 were/are one of such examples. The attention on actions, independence of opinions, and evidencebased management are the meta predispositions on which other predispositions are made. This second tier is about systems theory, and the third is made from the responsiveness, adaptability, agility and robustness that follows from one to another in the stated 3rd to be able to fully comprehend the described adaptive legal approaches suitable for the flexible and dynamic environment.

\section{The Systemic Approach Is Inevitable, but Not Enough for Good Regulation}

In the manner of the spirit of laws, systems theory is just a rational reflection of effective and efficient doings; the word "system" or "systematic" are many times provisory, even abused in legal drafts, where intuition prevails, despite the known psychological biases and/or failings of mental reasoning. In the more and more complex world, it is time to put legal reasoning on a higher level of scientific enquiry, cybernetic and/or systemic elements. Among psychological failings is also knowing, but not using systems theory in practice. System (gr. systèma, "an arrangement", from synistanai to combine, from syn- "together" + histanai "cause to stand" [Merriam-Webster, 2017]) is an assemblage or a combination of correlated things or parts forming a complex or unitary whole. "A system is an interconnected set of elements that is coherently organized in a way that achieves something... a system must consist of three kinds of things: elements, interconnections, and a function or purpose" (Meadows, 2008, p. 12). A system groups parts that act together for a common purpose. Systems are seen as feedback processes having a specific and orderly structure. A general approach for all special means is a systemic design that incorporates parts and their relations in a (decision-making) system. Its predisposition is that an observer finds facts based on his observing methods. In this approach along Protagoras's homo mensura fits also Berkeley's immaterialism (in which the only things we perceive are our perceptions, or esse est percipi, to be is to be perceived) (Berkeley, 2003) and Kant's Copernican turn (Kant, 2004) that abandons a study of reality per se in favour of the world-of-appearances and intrinsic structures of the mind that determine the nature of knowledge. This approach was further advanced in quantum theory: "[w]hat we observe is not nature itself but nature exposed to our method of questioning" (Heisenberg, 1958, p. 58). This understanding of the (unknowable) whole fully emerged in the previous century in systems theory (Ackoff, 1978; Beer, 1966; Bertalanffy, 1968; Forrester, 1968; Luhmann, 2013), as an interdisciplinary theory of systems that investigates phenomena in their relations and entirety. Tightly connected with systems theory are cybernetics or control and communication in the animal and the machine (Wiener, 1961): it is focused on signals, information, feedback and control. When people learn from the experience, they do this based on feedback loops that cause a dynamic behaviour of systems. To model the system there should be "closed boundary around the system, feedback loops within the boundary, level (stock) variables representing accumulations within the feedback loops, rate (flow) variables as activities within feedback loops and the goal, observed condition, detection and action based on discrepancy as components of rate variable" (Forrester, 
1961, p. 12). Regulatory means should in the future put greater attention on observation of inputs and outputs into a system, on feedbacks and changes in the environment vis$\grave{a}$-vis decisions made (observed patterns), to the state of stocks and flows according to current trends, in setting indicators that could in a relatively short period indicate an actual state of affairs and activate (due to exceeded thresholds) of pre-prepared/determined scenarios/rules concerning the established actual situation. The detection of discrepancy and action based on it vis-à-vis stocks is synonymous with a decision that changes the stocks-flows relation (a pattern). Feedback is "the mechanism (rule or information flow or signal) that allows a change in stock to affect a flow into or out of that same stock" (Meadows, 2008, p. 187). Feedback hence exists when two parts can affect each other (Ashby, 1957; Beer, 1995). Taken as a whole, system theory is nothing but real-time decision support (Burstein, Brézillon and Zaslavsky, 2010) that monitors activity (sensors or data-gathering instruments), transmits alerts to decision-makers when a change occurs based on preestablished thresholds, analyses data (the stored and updated data immediately or when needed) by decision support systems (statistical or other tools to assist decision making), provides advice as rules' input and executes rules. The monitored outputs of decisions/actions taken on the environment through feedback from data origination to decision use in a continuous loop provide a pattern that could be changed with new decisions that readjust relations between stocks and flows.

Although system theory puts high stakes on the power of feedback it has also its shortcomings. No subsystem per se does not have enough information to permit an accurate understanding of a wider system (society, nature). It is contrary - the latter gives meaning to the former: there will always be true statements, but not deducible from themselves, but solely from other, higher systems (Beer, 1994; McCulloch, 1945). It is hence the first element of the systems to have a closed boundary around the system (Forrester, 1961). The interdependence or relations among the system's parts warns against considering only data obtained through feedback into the regulatory cycle: such conclusions are based on connections and relations that evaluated rules as such neither formally nor de facto have - this proves Gödel's incompleteness theorem: "all consistent axiomatic formulations of number theory include undecidable propositions... any formal system that is interesting enough to formulate its consistency can prove its consistency if it is inconsistent" (Weisstein, 2015). Properties of the system are different from the properties of its parts. Feedback is necessary, but due also to cognitive errors, it does not always provide objective information on changes caused by people's actions. Feedback can fail to inform because it is only probabilistic (there is no certain, one-to-one correspondence between action and its result), incomplete (often people do not and cannot know the outcomes of alternative actions that could be taken), hidden (such as good/bad consequences), ambiguous (it is difficult to pin down what exactly led an action to be a beneficial or costly one), absent and biased. Along these fails are also flawed habits in monitoring feedback: people focus on positive co-occurrence, create self-fulfilling prophecies (expectation comes true because one believes in it and acts accordingly to fulfil it), fail to recognise their mistakes in hindsight (people fail to recognise they made any mistake at all), disproportionately seek feedback consistent with their self-image, accept positive and scrutinise negative feedback, 
code positive actions broadly and negative ones narrowly, attribute positive outcomes to self, negative ones to anyone or anything else, and misremember feedback sessions (Dunning, 2012, pp. 65-78). Along with these failings, there are also the hindsight bias (the after-the-fact propensity to think that we "knew it all along"), sampling bias (people pay less attention than they should to the unhappened things), post-hoc bias (people are tempted to infer a cause-and-effect relation when they witness only a sequence of events), confirmation bias (people search, interpret and recall only such information that confirms their prior beliefs or hypotheses) and other biases that are more expressive when only intuition is used instead of rigorous scientific methodology. To minimise the above-given biases, feedback becomes relevant with the ex-ante (as democratically as possible or otherwise impartial or professionally determined) established set of criteria/indicators/thresholds that measure changes in the environment and actions based upon it. The relevance of feedback is in its mimic of living beings that continuously assess data in the environment. Why should this be different for legal rules? Good regulation should thus also exhibit similar elements. They are presented in the next section.

\section{Responsiveness, Adaptability, Agility, Robustness}

Every service, every system behaves in a way that its structure allows it; a system encounters problem whenever its structure cannot adapt to different conditions. The latter can be seen as an exception, but changes are the sine qua non of life. The Nobel Prize-winning chemist Ilya Prigogine established that all sufficiently complex systems can develop unpredictable emergent behaviour ('the interaction of a system with the outside world, it's embedding in non-equilibrium conditions, may become in this way the starting point for the formation of new dynamic states of matter - dissipative structures' [Prigogine and Stengers, 1984, p. 143]) far from equilibrium (very small perturbations or fluctuations can become amplified into gigantic, structure-breaking waves). In such conditions, dissipative structures and/or a system may reorganise itself (self-reorganisation) in new order through fluctuations (Nicolis and Prigogine, 1977) (the example is chemical changes in ice by supplying heat towards the boiling water, vapour and steam). As ipso facto social systems are also dynamic and complex, they should be equipped with the appropriate dynamic, adaptable, robust and responsive tools by which the environment can be addressed (the social system will otherwise "regulate itself" - e.g., the emergence of new behaviour, fashion, customs, popular songs, movies and/or a spontaneous detour of traffic due to traffic accident). Giving up the illusion of certainty enables us to enjoy and explore the world's complexity in which we live by teaching how to recognise types and estimate degrees of uncertainty and to experiment with representations to find the most transparent way to communicate and explain risks. "There is a consensus today that the public has a right to information; but there is not yet a consensus, the public also has a right to get this information in a clear and not misleading way" (Gigerenzer, 2003). Like taxation, also information needs informed representation: "while right-to-know policies required simply that existing government reports and other documents be made available to the public, targeted transparency policies require that government agencies, companies, and other private-sector organisations collect, standardise, and release factual information to 
inform public choices" (Fung, Graham and Weil, 2007, p. 28). Even the most democratic approaches are of little value if people do not understand and use them accordingly. To survive, institutions need to retain and improve their alignment with the external world, (as for drivers to be agile on the road), so this should be similar for the law: be certain and at the same time agile, adaptable vis-à-vis context in which is used. The "good" side of the Covid19 crisis was that it allowed at least approximate daily monitoring of the state of affairs (the number of tested, infected and deceased people) and responding appropriately to changed conditions - this situation very plastically showed that responsiveness, adaptability, agility and robustness (RAAR) are needed in the law due to inevitability of dynamic changes.

On the other hand, RAAR can conflict with the principle of legal certainty. Of course, it is always better for the law to be certain, so it can be easily enforced and people can know what (not) to do, but as it is in all cases where words are used, there is always a degree of uncertainty (e.g. Who is "a fine man/lady"?). Therefore, within the mentioned degree the law should be accessible, as far as possible intelligible, clear and predictable. For the ECtHR, the general principle of legal certainty "requires that all law be sufficiently precise to allow the person - if need be, with appropriate advice - to foresee, to a degree that is reasonable in the circumstances, the consequences which a given action may entail" (Ječius v. Lithuania, no. 34578/97, § 56; Baranowski v. Poland, no. 28358/95, §§ 50-52 and Korchuganova v. Russia, no. 75039/01, § 47). The concept of legal certainty is recognised also as one of the general principles of European Union law by the European Court of Justice since the 1960s (Chalmers, Davies and Monti, 2014). Lon Fuller has enumerated eight principles of legality: “(1) a failure to achieve rules at all so that every issue must be decided on an ad hoc basis; (2) a failure to publicize, or at least to make available to the affected party, the rules he is expected to observe; (3) the abuse of retroactive legislation, which not only cannot itself guide to action, but undercuts the integrity of rules prospective in effect, since it puts them under the threat of retrospective change; (4) a failure to make rules understandable; (5) the enactment of contradictory rules or (6) rules that require conduct beyond the powers of the affected party; (7) introducing such frequent changes in the rules that the subject cannot orient his action by them; and, finally, (8) a failure of congruence between the rules as announced and their actual administration" (Fuller, 1969, p. 39). Fuller's second principle is Hayek's rule of law that "stripped of all technicalities ... [it] means that government in all its actions is bound by rules fixed and announced beforehand - rules which make it possible to foresee with fair certainty how the authority will use its coercive powers in given circumstances, and to plan one's individual affairs based on this knowledge" (Hayek, 2006, p. 75). On the other hand, "liberty is essential to leave room for the unforeseeable and unpredictable; we want it because we have learned to expect from it the opportunity of realizing many of our aims. It is because every individual knows so little and, in particular, because we rarely know which of us knows best that we trust the independent and competitive efforts of many to induce the emergence of what we shall want when we see it" (Hayek, 2011, p. 81). The rule of law can thus be seen as a proportionate RAAR expression of liberty.

The principle of legal certainty prohibits retroactive laws that should not take effect before they are published (Fuller's second principle), provided there is a time needed for 
the acknowledgement of new laws, known as vacatio legis (literally "law on holiday") i.e., an adaptive period between the announcement of a legal act and its formal validity. Within the requirement stated by the principle of promulgation, there is enough room for a diversity of techniques by which legal norms can be ascertainable. A publication of laws has been so far mostly implemented in the Official journals (OJ) in the paper form, while technological innovations have enabled the faster, "real-time" transfer and availability of information (e.g., the telephone, radio, television, smartphones, text messaging) needed to make relevant decisions/actions. The principle of legal certainty is in the latter case not endangered; quite contrary - it can be even closer to media and citizens (and their various electronic equipment). The usual thought about the rule of law is also that it "is significantly weakened, whenever norms are drafted in such a way that they cannot be known in advance, for this lack of certainty hampers citizens' self-determination and makes it impossible for them to carry out their own life plans" (Gómez, 2019, p. vi). On the other hand, it is also the indisputable fact that rules are used given the appropriate context of their environment. A realm of unknown future - that evolves in various, complex, exponential, uncertain ways - makes the previously enacted rules as not so known ones. Nevertheless, future can be foreseen more by i) the publication of rules and all the more ii) when the various, diverse and many people participate in addressing the complex future, and iii) when adaptive regulatory techniques are used. The concept of legal adaptability to changes in the environment is not contrary to the principle of legal certainty if laws are published before the entry into force when their inputs are made by the diverse people, who anticipate possible future scenarios. From a particular situation depends on how long the vacatio legis will be (in some cases of the Covid-19 situations, laws entered into force on the (same) day of their announcement). The publication of laws is also not endangered when these laws address different future situations (they always do so), according to their criteria. These situations are known in advance, so the public can be acknowledged on their effects and/or consequences. RAAR is thus not in conflict with the principle of legal certainty. The real question, therefore, is how laws can be made now and be tightly adaptable in real-time to anticipated future situations, and/or how the classical (almost still mechanical) procedure of legal drafting can be shortened or replaced with other, more advanced ways.

Responsiveness to situations can be understood within the valid law, or as a prestige of laws' adaptability through formal procedures. There is still an illusion present that drafting of general legal rules can function as a machine that steps need only be carried out. The basis of that illusion is an assumption the world and things on it stay more or less the same. The world is the changing and dynamic place now more than ever, while many regulators and/or decision-makers act as there is only one (i.e., their) correct answer, and it needs only to be implemented. Although they stick to this "correct answer" (with the help of parliamentarian majority) this de facto widens possibilities for damages and lost opportunities. To gain a better alignment of regulation with the dynamic and complex environment, the first should adapt to the second and not vice versa. The framework, goals and alternative methods of achieving them must be determined ex-ante and the best method among them ex-post chosen. The framework's usefulness is understood 
in its ability to identify typical regulatory problems, in its ability to anticipate errors, and to offer alternatives that maximise not only correlation but causation (there is e.g. a correlation present between wing feathers and flight, which, for the mythological Icarus and other people who tried to fly this way, ended badly) between the phenomena and their connections. Any approach or instrument that addresses a long-term solution will eventually deviate from an outlined path; without adjusting and correcting it, it will cause unwanted, side effects. Understanding the mechanism of action is sufficient only for the ability to act, while it is only through the experimentation and measurement of different conditions able to identify circumstances (within which a mechanism produces desired results) that allow good (causal) prediction and action. Adaptation as an ability to adjust to different conditions reflects the combination of speed and capacity to handle complexity. The latter is based on Ashby's law of requisite variety (Ashby, 1957): the only way to destroy the variety (complexity) is through the same amount of variety (flexibility, resilience). More advanced adaptation tools (enumerated from less to more flexible: the sunset clauses, legal experiments, strategy, scenario planning, collective wisdom and measure-and-react approach) reflect also agility as the ability to anticipate future changes and push oneself to prepare/adjust quickly to dynamic changes. The latter's result is robustness as "the potential for success under varying future circumstances or scenarios", while the former's is responsiveness as the ability "to rapidly 1) sense a change in environment; 2) conceptualise a response to that change; and 3) reconfigure resources to execute the response" (Bettis and Hitt, 1995). The notions that represent the RAAR abbreviation can be seen as goals, while there is one general (system theory) and several special means (sunset clauses, legal experiments, strategy, scenario planning, collective wisdom and measure-and-react approach) by which these goals are achieved. These means represent "the very core of why we do science: to prevent ourselves from being misled by our own atomised experiences and prejudices" (Goldacre, 2008). In the RAAR frame, regulatory changes are not causes, which drive a need for agility, but means that reflect the latter, aligned with the external and internal dynamics and available technology.

\section{Adaptive Regulatory Techniques}

Restrictive measures in the Covid-19 crisis have shown a dependence of regulatory systems on people (especially in the implementation phase), but this cannot mean that regulatory technics cannot be further improved in the enacting phase. The complex environment with a variety of structures, actions and processes cause only limited possibilities for the effective administration of dynamic, exponential, emergent and hence mostly unpredictable affairs. Here regulators could not count on precise intentions or long-term predictions and more on fast reactions to changes. The downside of the existing, classic mode of regulation is its static nature (the adaptive elements are here the interpretation of the text, undetermined legal motions, principles and discretion) that lacks (at least semi-) automatic controls that could "force" regulators to re-evaluate situations. Having this goal in mind, this section presents a typology of regulation based on the high/low elements of automatization of knowledge and adaptation/standardisation vis-à-vis future changes and consequential regulatory adaptations towards such changes (the inner quadrant in Figure 1 
below). The interaction of these two elements shows also decision-maker active/passive approaches towards regulation that at the same time reflect also interaction between the individual/collective and tacit/explicit knowledge on regulatory approaches vis-à-vis their robustness (the external quadrant in Figure 1 below).

The four-type division is similar to four of Lam's (Lam, 2000) categories of knowledge: individual-explicit to "embrained" (that depends on the individual's skills and cognitive capacities based on formal, abstract knowledge), individual-tacit to "embodied" (practice, experiences, context-specific), collective-explicit to "encoded" (codifications, written rules and procedures) and collective-tacit to "embedded" knowledge (routines, shared norms, beliefs). Given the four-part typology of standardisation and automatization of knowledge, there are also four approaches: react and anticipate, react and measure, anticipate and react, measure and react. Based on these approaches, regulation can be divided into professional, ad hoc, machine and J-form type. Professional derives its capabilities from the formal knowledge of highly trained experts (individual-explicit, embrained, react and anticipate), ad hoc from diverse know-how and practical problem-solving skills (individual-tacit, embodied, react and measure), machine from the systemic approach, specialisation and formal standardisation (collective-explicit, encoded, anticipate and react) and J-form from team relations and shared culture (collective-tacit, embedded, measure and react). The J-form stands for the "Japanese type" of the organisation that fuses machine stability and efficiency with the ad hoc flexibility and team dynamics, present in Honda, Canon, Matsushita, and NEC as "knowledge-creating companies" (Nonaka, Takeuchi and Nonaka, 1995).

Figure 1: The typology of regulation

\begin{tabular}{|c|c|c|c|}
\hline Professional regulation & & & Machine regulation \\
\hline $\begin{array}{l}\text { React and anticipate } \\
\text { (individual-explicit) } \\
\text { Adaptation/ }\end{array}$ & $\begin{array}{l}\text { Legal experiments } \\
\text { Sunset clauses } \\
\text { Expert intelligence }\end{array}$ & $\begin{array}{l}\text { Adaptable norms } \\
\text { (Negative) scenarios } \\
\text { Emergent strategies }\end{array}$ & $\begin{array}{l}\text { Anticipate and react } \\
\text { (collective-explicit) }\end{array}$ \\
\hline \multirow[t]{2}{*}{$\begin{array}{l}\text { standardisation } \\
\text { React and measure } \\
\text { (individual-tacit) }\end{array}$} & $\begin{array}{l}\text { Henry VIII clauses } \\
\text { Classic regulation } \\
\text { (interpretation, undeterminate } \\
\text { legal notions, principles) }\end{array}$ & $\begin{array}{l}\text { Collective intelligence } \\
\text { Legal experiments } \\
\text { Public opinion (values) }\end{array}$ & $\begin{array}{l}\text { Measure and react } \\
\text { (collective-tacit) }\end{array}$ \\
\hline & Automatisation & of knowledge & + \\
\hline Ad hoc regulation & & & $\mathrm{J}$-form regulation \\
\hline
\end{tabular}


In ad hoc regulation (that responds on examples that come easily to a person's mind [e.g., recent scandals], and regulates accordingly) fits mainly classic regulation. From the point of adaptation in this type could be put also Henry VIII clauses. ${ }^{5}$ As the first and the second are well known, the paper goes to professional regulation where only (due to the known notion of expert intelligence) the sunset clauses and legal experiments are briefly explained. Sunset clauses can be used individually or in connection with Henry VIII/ouster clauses. ${ }^{6}$ A sunset clause is designed to force the Parliament to consider regulatory reform on an agency-by-agency and/or on Act-by-Act basis. It provides that an evaluated agency or Act, together with its rules and regulations, will cease to exist at a certain date except when the Parliament specifically enacts legislation that extends the agency's or Act's life (Breyer, Stewart, Sunstein and Vermeule, 2006). Sunset provisions differ greatly in their details, but they all periodically compel the Parliament to reexamine its delegations of authority and to assess the utility of those delegations in the light of experience/results. The J-form of regulation can fit the public opinion, legal experiments, and collective intelligence. As public opinion is well-known, we will proceed to legal experiments. Legislation/regulation is always an experiment with human destinies; this all the more stands for experimental legislation. The latter 'implies submitting new rules to a 'reality check', but allows legislators to gather more information, progressively extend the new rules to other parts of the jurisdiction in question, and adapt and improve existing laws based on evidence of what works and what does not" (Ranchordás, 2014, p. 8). French "experimental stance" goes back to Descartes, who in 1673 discussed the methods of better managing reason and finding truth in science (Descartes, Spinoza and Leibniz, 1974), to the time of Louis XVI (1754-1793), who has for the improvement of his administration experimented with the reintroduction of the provincial parliaments, while the most famous name on the field of experimentation is the French physiologist Claude Bernard (1813-1878), who described what makes a scientific theory good. ${ }^{7}$ Modern French legislation has been met with the question of legal experimentation with the Higher Education Act of 1984. Article 21 defined that all public scientific, cultural and professional institutions must be set up by decree. The Act gave the option to withdraw from some articles of law for five years. Exceptions were designed to test the new ways of organising institutions and their management. The law has come under the review by the Constitutional Council (decision no. 93-322 DC of 28.7.1993), which has found the law unconstitutional, but it also defined the permitted way of "experimental regulation". 8 Another example of

\footnotetext{
${ }^{5}$ A Henry VIII clause is a provision, contained in primary legislation, which grants to the Executive the power, by means of secondary legislation, to amend primary or secondary legislation (Pečarič, 2016). The example of this clause is found in Article 290 TFEU.

${ }^{6}$ Statutory provisions permitting primary legislation to be modified by transitional regulations should generally be subject to a sunset clause of three years (Bigwood, 2003).

${ }^{7}$ Theories are only hypotheses, verified by more or less numerous facts. Those verified by the most facts are the best, but even then, they are never final, never to be absolutely believed. Proof that a given condition always precedes or accompanies a phenomenon does not warrant concluding with certainty that a given condition is the immediate cause of that phenomenon. It must still be established that when this condition is removed, the phenomenon will no longer appear (Bernard, 2012).

${ }^{8}$ Considering that it is open to the legislator to provide a possibility of experiments comprising derogations
} 
experimentation refers to the law on Corsica (La Loi du 22 Janvier 2002 relative à la Corse), which the Constitutional Council declared unconstitutional because the legislator should not delegate powers that were under the Constitution reserved only for him. Moreover due to this fact France in 2003 adopted the constitutional law in which affirmed constitutional amendments that were related to the conditions for experimentation. Article 37-1 provides that "[s]tatutes and regulations may contain provisions enacted on an experimental basis for limited purposes and duration", while the fourth paragraph of Article 72 provides that

[i]n the manner provided for by an Institutional Act, except where the essential conditions for the exercise of public freedoms or a right guaranteed by the Constitution are affected, territorial communities or associations thereof may, where provision is made by statute or regulation, as the case may be, derogate on an experimental basis for limited purposes and duration from provisions laid down by statute or regulation governing the exercise of their powers.

Regarding the conditions for experimentation, an experiment must be concluded before the expiration of the term set by enabling legislation. There are three options available: 1) extension (under determined conditions) and possible modification of testing in a fixed time. The unequal treatment resulting from the experiment must be time-limited because the too-long testing produces irreversible effects and disparity of law on a tested territory; 2 ) the maintenance and generalisation of the action on an experimental basis. The standards set on a trial basis may vary by communities, while legislature then evaluates them and decides on successful experiments; 3) an abandonment of the experiment. The law determines the ending conditions of the experiment and where applicable, also transitional provisions. In the end, prior law is applicable again, but it may be also the subject of modifications (Pečarič, 2011). While legal experiments are typically the first step towards permanent legislation, sunset clauses are usually put to fulfil a specific mission and then cease after a fixed period if they are not prolonged before the expiration date.

Collective intelligence represents a group of various independent and ordinary people judge as well as or better than experts. People outside the government have diverse knowledge, different opinions, work at different posts, come from different backgrounds, and know many various things. The benefits of diversity, independence and aggregation of opinions are included not only in situations where people work in different places or perform different tasks: when diverse individuals concentrate on the same problem in parallel, their aggregate and/or median solution will be usually better than that of any single person. This phenomenon is known as the "wisdom of crowds" (Surowiecki, 2005; Landemore and Elster, 2012) or "collective intelligence" (Woolley, Chabris, Pentland, Hashmi and Malone, 2010; Leimeister, 2010).

In the machine, regulation is found the emergent strategies, negative scenarios, and adaptable norms. Mintzberg has divided strategies as ex post facto results of decisional

from the primary rules to enable to subsequently adopt, in the light of their results appropriate new changes in the missions of the category of establishments in question; whereas, however, it is incumbent on him to define precisely the nature and scope of these experiments, the cases in which they can be undertaken, the conditions and procedures according to which they must be the subject of an assessment leading to their continuation, their modification, their generalization or their abandonment (at 9). 
behaviour and as strategies as a priori guidelines to decision-making. A priori strategy is the intended strategy - in a realised part it is a deliberate strategy, in the non-realised one, it is an unrealised strategy. Ex post facto strategy is the realised strategy; it was never intended or got changed along the way - in this part, it is understood as an emergent strategy (Mintzberg, 1978). "The fundamental difference between deliberate and emergent strategy is that whereas the former focuses on direction and control-getting desired things done the latter opens up this notion of 'strategic learning'. Defining strategy as intended... effectively precludes the notion of strategic learning. Once the intentions have been set, attention is riveted on realizing them, not on adapting them... The emergent strategy itself implies learning what works-taking one action at a time in search of that viable pattern or consistency. It is important to remember that emergent strategy means, not chaos, but, in essence, unintended order" (Mintzberg and Waters, 1985, pp. 270-271). In both cases, "actively monitoring, understanding, and controlling the criteria by which dayto-day resource allocation decisions are made at all levels of the organization are among the highest-impact challenges a manager can tackle in the strategy development process" (Christensen and Raynor, 2013). In real-life, there is an ideal type, neither of the intended nor of the emergent strategy, but a combination of both, where the strategy is implemented on the one hand under the original intentions and the other (still within the framework of the basic postulates of an institution) with currently changing conditions. Such differentiation of strategies also allows a fundamental understanding of the implementation of regulations, which, due to changing conditions in a complex environment, must necessarily contain elements of adaptation (which often lacks in regulation).

Instead of investing large resources on accurate future predictions, regulators could refine and enhance their ability to detect and measure changes and act accordingly, i.e. to learn what is effective and efficient as a reaction to unexpected opportunities and challenges. Protagoras saying that "man is the measure of all things" could be thus changed into "the measure of all things is the measure (and reaction)". The illusion of certainty could be therefore dispelled with the measure-and-react (emergent) strategy: "[r]ather than predicting how people will behave and attempting to design ways to make consumers respond in a particular way... we can instead measure directly how they respond to a whole range of possibilities, and react accordingly. In other words, the shift from 'predict and control' to 'measure and react' is not just technological... but psychological. Only once we concede that we cannot depend on our ability to predict the future are we open to a process that discovers it" (Watts, 2011, p. 196). The measure-and-react (emergent) strategy opens new possibilities to experiment with new things, approaches or methods. Although science is in large part based on experiments, legal science uses them very rarely. Although science is essentially based on experiments, legal science rarely uses them, which to a certain extent represents the paradox of legal "science". Relying only on past experiences of existing regulations is tantamount to carrying out a particular experiment without reconfirming it. History does not repeat itself, so it is not a completely reliable element to rely on completely (sometimes a slight change could lead to a completely different historical event or result). 
Confirmation bias as an exclusive and intentional search only for confirming evidence is one of the first obstacles towards good regulation. This bias can be found already in cataphatic theology in which knowledge of God is obtained through defining God with positive statements (Oxford, 2016). Other intuitive methods (e.g., the rule of thumb, educated guesses, common sense) are used to find satisfactory solutions, while the negative approach ("Do not... !") is founded already in the Ten Commandments and in the primal legal principle of neminem laedere ("Do no harm"; in medicine, it is known as primum non nocere - first, do no harm). The apophatic, negative approach is also a solution to the most famous Wason selection task, the four-card problem in the study of deductive reasoning (Wason, 1968). It is surprising to note that regulators or authorities usually do not use the elimination system as negative parts, determined not to fit into a particular set. A series of corroborative facts is not necessarily evidence (Taleb, 2010); inner consistency can have a hypnotic effect that finds our reason inattentive. To prevent this naïve empiricism, we can get closer to the truth by using negative instances, not by verification: "[y]ou know what is wrong with a lot more confidence than you know what is right" (Merriam-Webster, 2020). Future regulation can be in this manner tested with the remote negatively imagined consequences: they can be more easily imagined than what will happen for certain. What we do not want is hence the indirect approach towards what can be done. With such negative scenarios also, rules can be formed that already at their enactment determine more than one negative consequence and regulates accordingly also appropriate measures (e.g., death casualties in traffic $=$ basic number $+10 \% ;+50 \% ;+75 \%$ or a number of illegal migrants $+10 \% ;+50 \% ;+75 \%$, etc. $)$.

\section{Conclusion}

If governments through public participation fill the content of the RAAR adaptive regulatory techniques and through them obtain aggregated public preferences and values, the rule of law can be closer to other important principles, such as democracy, justice, social equality, or human rights. This change should be seen more in results than in statements; there is no big use of the law that promotes democratic values without such consequences. The expressive function of law should give place to its operational, consequential version. Transparency promotes accountability and allows people to take more informed decision/action based on the obtained information, but there are caveats also. In support of regulatory action, there is saying that "after the war, we all are generals" i.e., we know everything how it should be done. In practice, we can perceive it when we say: "Yes, that is obvious"! Well, nothing is obvious - it could be also otherwise. Many times, it is about a cognitive error that post-festum seeks arguments only for its own (individual) belief, but not for opposite ones, which both come from the (neglected) whole of all "beliefs" (base rate). In this sense, it is also easier for the Constitutional Court (and all of us now) to evaluate measures at a time when the situation is already clearer, while the regulator must act in much greater uncertainty in a time when measures are enacted. We need to put ourselves in the "shoes" of the decision-maker at a given moment and judge what we could have done differently with that set of information that was then available. Being wrong is humanly said; it is even more human to monitor your decisions, admit 
a mistake when necessary, and adapt to the new situation as soon as possible. From this crisis, it can be understood that the regulation of future, changing and uncertain situations are more difficult than in relatively clear cases. More flexible legislation is closely linked to people's confidence in the functioning of government. An example might be Sweden, where solely based on trust in people and recommendations are given, the number of deaths per 1 million people is smaller than in many other countries that have taken more rigorous actions. The Swedes might cultivate a greater degree of trust in public institutions, which is a prerequisite for easier implementation of legislation. The Corona-crisis will, therefore, strengthen the role of those countries that have introduced safeguards promptly and will subsequently loosen them and, eventually, eliminate them. The role of public administration can be strengthened or reduced in general, or in times of crisis, depending on the effectiveness of the state in making appropriate, urgent, and proportionate decisions in given situations. The public will see the performance of public institutions as positive, where the results will be good compared to other countries and vice versa, where they will be poor. This is where the public administration could use information technology to maximise the processing of many applications and data, and here also the proposed typology of adaptable regulation might be helpful.

\section{References}

Ackoff, R. L. (1978). The Art of Problem Solving: Accompanied by Ackoff's Fables. New York: John Wiley \& Sons.

Ashby, W. R. (1957). An Introduction to Cybernetics. London: Chapman and Hall.

Baldwin, R., Cave, M. and Lodge, M. (2012). The Oxford Handbook of Regulation. Oxford; New York: Oxford University Press.

Baldwin, R., Cave, M. and Lodge, M. (2013). Understanding Regulation: Theory, Strategy, and Practice. New York: Oxford University Press.

Banasiewicz, A. D. (2019). Evidence-Based Decision-Making. London: Routledge.

Beer, S. (1966). Decision and Control: The Meaning of Operational Research and Management Cybernetics. Chichester: John Wiley \& Sons.

Beer, S. (1994). Beyond Dispute: The Invention of Team Syntegrity. Chichester; New York: Wiley.

Beer, S. (1995). Designing Freedom. New Jersey: Wiley.

Beer, S. (2002). What is cybernetics. Kybernetes, 31(2), 209-219. doi:10.1108/03684920210417283.

Berkeley, G. (2003). A Treatise Concerning the Principles of Human Knowledge. Dover Publications, Inc.

Bernard, C. (2012). An Introduction to the Study of Experimental Medicine. Courier Corporation.

Bertalanffy, L. V. (1968). General system theory: foundations, development, applications. New York: George Braziller. 
Bettis, R. A. and Hitt, M. A. (1995). The new competitive landscape. Strategic management journal, 16(S1), 7-19. Retrieved from https://onlinelibrary.wiley.com/doi/abs/10.1002/smj.4250160915.

Bigwood, R. (2003). The Statute. Wellington: LexisNexis. Retrieved from http://books. google.com/books?id=SciYAAAACAAJ\&hl=\&source=gbs_api.

Breyer, S. G., Stewart, R. B., Sunstein, C. R. and Vermeule, A. (2006). Administrative Law and Regulatory Policy: Problems, Text, and Cases. New York, NY: Aspen Publishers. Burstein, F., Brézillon, P. and Zaslavsky, A. (2010). Supporting Real Time DecisionMaking. New York, Dordrecht, Heidelberg, London: Springer Science \& Business Media. Chalmers, D., Davies, G. and Monti, G. (2014). European Union Law. Oxford: Cambridge University Press. Retrieved from http://books.google.com/books?id=GjuNAwAAQBAJ\& $\mathrm{hl}=\&$ source $=\mathrm{gbs} \_$api.

Christensen, C. and Raynor, M. (2013). The innovator's solution: Creating and sustaining successful growth. Boston: Harvard Business Review Press. Retrieved from https://books. google.com/books?hl=en\&lr=\&id=I5nBAgAAQBAJ\&oi=fnd\&pg=PR5\&dq=The+innovator's+solution\&ots=-3A0Wkbxdq\&sig=opbm-gyese4YkqA6SzKJdGb6VSg.

Descartes, R., Spinoza, B. D. and Leibniz, G. W. V. (1974). The Rationalists: Descartes: Discourse on Method \& Meditations; Spinoza: Ethics; Leibniz: Monadology \& Discourse on Metaphysics. New York: Anchor Books.

Dirk Helbing, B. S. F., Gerd Gigerenzer, Ernst Hafen, Michael Hagner, Yvonne Hofstetter, Jeroen van den Hoven, Roberto V. Zicari, Andrej Zwitter. (2020). Will Democracy Survive Big Data and Artificial Intelligence? Retrieved April 9, 2020, from https://www.scientificamerican.com/article/will-democracy-survive-big-data-and-artificial-intelligence.

Dunleavy, P., Margetts, H., Tinkler, J. and Bastow, S. (2006). Digital era governance: IT corporations, the state, and e-government. New York: Oxford University Press.

Dunning, D. (2012). Self-Insight. New York and Hove: Psychology Press.

Emerson, R. W. (1875). Letters and Social Aims. Boston: Houghton, Mifflin.

Forrester, J. W. (1961). Industrial Dynamics. Cambridge: MIT Press.

Forrester, J. W. (1968). Principles of Systems. Waltham, MA: Pegasus Communications.

Foucault, M. (2013). Dits et Ecrits, tome 2: 1976-1988. Paris: French and European Publications Inc.

Fukuyama, F. (2014). Political Order and Political Decay: From the Industrial Revolution to the Globalization of Democracy. London: Farrar, Straus and Giroux.

Fuller, L. L. (1969). The Morality of Law. New Haven and London: Yale University Press. Fung, A., Graham, M. and Weil, D. (2007). Full Disclosure. Cambridge: Cambridge University Press. Retrieved from http://books.google.com/books?id=vSJcyLQgrKcC\&hl=\& source $=$ gbs_api.

Keillor, G. (2016). A Prairie Home Companion with Garrison Keillor. Retrieved October 13, 2019, from http://prairiehome.org.

Gigerenzer, G. (2003). Reckoning with Risk: Learning to Live with Uncertainty (e-book ed.). London: Penguin UK.

Gigerenzer, G. and Engel, C. (2006). Heuristics and the Law. Cambridge, MA: MIT Press. Goldacre, B. (2008). Bad Science. London: HarperCollins UK. 
Gómez, V. Z. (2019). The Art of Legislating. Cham: Springer Nature.

Gorddard, R., Colloff, M. J., Wise, R. M., Ware, D. and Dunlop, M. (2016). Values, rules and knowledge: adaptation as change in the decision context. Environmental Science \& Policy, 57, 60-69. Retrieved from https://www.sciencedirect.com/science/article/pii/S1462901115301210.

Hayek, F. A. (2006). The Road to Serfdom. London; New York: Routledge.

Hayek, F. A. (2011). The Constitution of Liberty: The Definitive Edition. Chicago: University Of Chicago Press.

Heisenberg, W. (1958). Physics and Philosophy: The Revolution in Modern Science. New York: Harper \& Brothers Publishers.

Hood, C., Rothstein, H. and Baldwin, R. (2001). The Government of Risk: Understanding Risk Regulation Regimes. Oxford: Oxford University Press.

Horwitz, A. V. (2013). The Logic of Social Control. New Brunswick: Springer Science \& Business Media. Retrieved from https://play.google.com/store/books/details?id=97ReBAAAQBAJ\&source=gbs_api.

Kant, I. (2004). Immanuel Kant: Prolegomena to Any Future Metaphysics: That Will Be Able to Come Forward as Science: With Selections from the Critique of Pure Reason. Cambridge: Cambridge University Press.

Kruger, J. and Dunning, D. (1999). Unskilled and unaware of it: how difficulties in recognizing one's own incompetence lead to inflated self-assessments. J Pers Soc Psychol, 77(6), 1121-1134. doi:10.1037//0022-3514.77.6.1121.

Lam, A. (2000). Tacit Knowledge, Organizational Learning and Societal Institutions: An Integrated Framework. Organization Studies, 21(3), 487-513. doi:10.1177/0170840600213001.

Landemore, H. and Elster, J. (2012). Collective Wisdom: Principles and Mechanisms. New York: Cambridge University Press.

Lazarsfeld, P. F. (1949). The American Soldier-An Expository Review. The Public Opinion Quarterly, 13(3), 377-404. Retrieved from https://www.jstor.org/stable/2745717.

Leimeister, J. M. (2010). Collective intelligence. Business \& Information Systems Engineering, 2(4), 245-248. Retrieved from https://link.springer.com/article/10.1007/s12599010-0114-8.

Lodge, M. and Wegrich, K. (2012). Managing Regulation. London: Macmillan International Higher Education.

Luhmann, N. (2013). Introduction to Systems Theory. Cambridge, UK; Malden, MA: Polity Press.

Manson, M. (2016). The Subtle Art of Not Giving $a F^{*} c k$. New York: HarperCollins. Retrieved from https://play.google.com/store/books/details?id=yng_CwAAQBAJ\&source=gbs _api.

McCulloch, W. S. (1945). A heterarchy of values determined by the topology of nervous nets. Bulletin of Mathematical Biophysics, 7(2), 89-93. doi:10.1007/BF02478457.

Meadows, D. H. (2008). Thinking in Systems: A Primer. London: Chelsea Green Publishing. 
Merriam-Webster. (2017). Definition of SYSTEM. Retrieved from https://www.merriamwebster.com/dictionary/system.

Merriam-Webster. (2020). Definition of Crisis. Retrieved April 27, 2020, from https:// www.merriam-webster.com/dictionary/crisis?utm campaign=sd\&utm medium=serp\& utm $\_$source=jsonld.

Mintzberg, H. (1978). Patterns in strategy formation. Management science, 24(9), 934-948. Retrieved from https://pubsonline.informs.org/doi/abs/10.1287/mnsc.24.9.934.

Mintzberg, H. and Waters, J. A. (1985). Of strategies, deliberate and emergent. Strategic management journal, 6(3), 257-272.

Mlodinow, L. (2008). The Drunkard's Walk: How Randomness Rules Our Lives. New York: Pantheon Books.

Mlodinow, L. (2013). Subliminal: How Your Unconscious Mind Rules Your Behavior. New York: Pantheon Books.

Mlodinow, L. (2018). Elastic. Vintage. Retrieved from http://books.google.com/books?id= _BEcDgAAQBAJ\&hl=\&source=gbs_api.

Montesquieu, C. B. D. (2004). The Spirit of Laws. Indianapolis: Liberty Fund Inc.

Morgan, B. and Yeung, K. (2007). An Introduction to Law and Regulation: Text and Materials. Cambridge: Cambridge University Press.

Münsterberg, H. (1908). On the witness stand: Essays on psychology and crime. New York: Doubleday, Page.

Nicolis, G. and Prigogine, I. (1977). Self-organization in nonequilibrium systems: from dissipative structures to order through fluctuations. Wiley.

Nonaka, I., Takeuchi, H. and Nonaka. (1995). The Knowledge-creating Company. New York: OUP USA. Retrieved from http://books.google.com/books?id=B-qxrPaU1-MC\&hl $=\&$ source $=$ gbs $\_$api.

Ogus, A. (2003). Regulatory Institutions and Structures. Retrieved from http://papers.ssrn. com/abstract $=368572$.

Oxford, D. (2016). Cataphatic - definition of cataphatic in English from the Oxford dictionary. Retrieved from http://www.oxforddictionaries.com/definition/english/cataphatic.

Pasnau, R. (2018). After Certainty. Oxford University Press. Retrieved from http://books. google.com/books?id=WoM8DwAAQBAJ\&hl=\&source=gbs_api.

Pečarič, M. (2011). A Dynamic Reflection on the Factual State of Affairs through an Experimental Norm. Legisprudence, 5(3), 273-295. doi:10.5235/175214611799248887.

Pečarič, M. (2016). An old absolutist amending clause as the "new" instrument of delegated legislation. The Theory and Practice of Legislation, 4(1), 1-26. Retrieved from https://www.tandfonline.com/doi/abs/10.1080/20508840.2016.1147189.

Plato. (2000). The Republic. Cambridge: Cambridge University Press.

Prigogine, I. and Stengers, I. (1984). Order Out of Chaos. New York, N.Y.: Bantam Books. Ranchordás, S. (2014). Constitutional Sunsets and Experimental Legislation. Cheltenham, UK + Northampton, MA, USA: Edward Elgar Publishing. Retrieved from https://play.google.com/store/books/details?id=LC21BQAAQBAJ\&source=gbs_api.

Rifkin, E. and Bouwer, E. (2007). The Illusion of Certainty: Health Benefits and Risks. New York, NY: Springer. 
Rousseau, M. (2013). The Oxford Handbook of Evidence-Based Management. Oxford: Oxford University Press.

Sunstein, C. R. (2016). The Ethics of Influence: Government in the Age of Behavioral Science. New York: Cambridge University Press.

Sunstein, C. R. and Reisch, L. A. (2019). Trusting Nudges. London: Routledge. Retrieved from https://play.google.com/store/books/details?id=AHWCDwAAQBAJ\&source=gbs -api.

Surowiecki, J. (2005). The Wisdom of Crowds. New York, NY: Anchor.

Taleb, N. N. (2010). The Black Swan: The Impact of the Highly Improbable Fragility. New York: Random House Publishing Group.

Wason, P. C. (1968). Reasoning about a rule. Quarterly Journal of Experimental Psychology, 20(3), 273-281. doi:10.1080/14640746808400161.

Watts, D. J. (2011). Everything Is Obvious: *Once You Know the Answer. New York: Crown Publishing Group.

Weisstein, E. W. (2015). Gödel's Incompleteness Theorem - from Wolfram MathWorld. Retrieved from http://mathworld.wolfram.com/GoedelsIncompletenessTheorem.html.

Wiener, N. (1961). Cybernetics or Control and Communication in the Animal and the Machine. Cambridge: MIT Press.

Woolley, A. W., Chabris, C. F., Pentland, A., Hashmi, N. and Malone, T. W. (2010). Evidence for a Collective Intelligence Factor in the Performance of Human Groups. Science, 330(6004), 686-688. doi:10.1126/science.1193147. 